\title{
Exploration and Practice of Multi-Party Cooperative Education Mode Under the Background of New Engineering*
}

\author{
Liyong Zhang ${ }^{1}$ \\ Hebei Agricultural University \\ Junliang $\mathrm{Liu}^{4}$ \\ Hebei Agricultural University
}

\author{
Xiaoyan Zhang $^{2}$ \\ Hebei Agricultural University \\ Hongying Yuan ${ }^{5}$ \\ Hebei Agricultural University
}

\author{
Tiejian Zhang ${ }^{3}$ \\ Hebei Agricultural University \\ Zhijian Shi ${ }^{6}$ \\ Hebei Agricultural University
}

\begin{abstract}
Multi-party cooperative education is one of the important contents in the construction of new engineering, and also an effective way to improve the quality of higher engineering education. By using the methods of literature analysis and case study, this study analyzes the defects of the traditional education mode in colleges and universities, and introduces the multi-party cooperative education mode which meets the requirements of new engineering and covers "family-school-internship unit-society". Then this study puts forward the concrete implementation way of multi-party cooperative education mode in engineering education, namely, to strengthen the psychological quality and gratitude consciousness of college students through family emotion education, to teach the basic knowledge and professional ability to college students through school professional education, to train the practical skills and innovative consciousness of college students through the internship unit, and to promote college students to further understand and fulfil social and professional responsibilities through the social environment. Through three-year application practice test, it is found that the research has played a positive role in training innovative advanced engineering talents and promoting the further development of new engineer education.
\end{abstract}

\section{Keywords}

New Engineering $\bullet$ Family-School-Internship Unit-Society $\bullet$ Cooperative Education

\footnotetext{
*This work was supported by Research and practice project of higher education teaching reform in Hebei province (No. 2017GJJG052).

${ }^{1}$ Institute of Urban and Rural Construction, Hebei Agricultural University, Baoding 071001, China. Email: 344044154@qq.com ${ }^{2}$ Institute of Urban and Rural Construction, Hebei Agricultural University, Baoding 071001, China. Email: yan_850404@163.om

${ }^{3}$ Institute of Urban and Rural Construction, Hebei Agricultural University, Baoding 071001, China. Email: 258507511 @qq.com ${ }^{4}$ Correspondence to: Junliang Liu. Institute of Urban and Rural Construction, Hebei Agricultural University, Baoding 071001, China. Email: hb-lj1@163.com

${ }^{5}$ Institute of Urban and Rural Construction, Hebei Agricultural University, Baoding 071001, China. Email: 1289734893@qq.com

${ }^{6}$ Institute of Urban and Rural Construction, Hebei Agricultural University, Baoding 071001, China. Email: 56226207@qq.com

Citation: Zhang, L. Y., Zhang, X. Y., Zhang, T. J., Liu, J. L., Yuan, H. Y., Shi, Z. J. (2018). Exploration and Practice of Multi-Party Cooperative Education Mode Under the Background of New Engineering. Educational Sciences: Theory \& Practice, 18(5), 2019-2026. http://dx.doi.org/10.12738/estp.2018.5.101
} 
The connotation of the construction of new engineering in higher education is to train the future diversified and innovative engineering talents by strengthening moral education and cultivating people (Zhong, 2017), and to emphasize the construction of multi-party cooperative education as an aspect of the construction of new engineering (Lin, 2017). Combined with the background of new engineering and professional certification, this study explores the multi-party collaborative education mode of engineering.

The report of the 19th National Congress of the Communist Party of China clearly puts forward "deepening the integration of industry and education, cooperation between schools and enterprises, and realizing the connotative development of higher education" to meet the domestic economic sustainable development take the highest position in international competition. However, the practice has proved that there are different degrees of distance or even dislocation between the graduates who have been cultivated under the traditional education mode of engineering and the demand for talents in the new era. In order to solve this contradiction, that state puts forward new engineering construction action in due time, requiring engineering majors to seize the historical opportunity, cooperate with each other, and improve the quality of education as a whole. The focus issue is how to construct the education system integrating production with education and cooperation between schools and enterprises, and to carry out and improve it, which is also the problem that the local colleges and universities must pay attention to and solve urgently. Therefore, based on the concept of new engineering construction, the multi-party cooperative education mode and its implementation approach are put forward so as to cultivate innovative advanced engineering talents meeting the requirements. Based on the analysis of the defects of traditional education mode and combined with the requirements of new engineering construction, this study explores multi-party cooperative education mode which can meet the requirements of multi parties, as well as discusses the ways to implement this mode and tests it.

\section{Dislocation analysis between the cultivated talents by traditional education mode and the demand of new era}

After 40 years of reform and opening-up, China's higher education has been on the right track and developed vigorously. Since the 21 st century, many engineering application disciplines have entered the fast track of rapid development and the number of students has created new high with the sustainable high-speed growth of social economy. Up to now, China's higher engineering education has made great achievements and a system of higher engineering education with the largest teaching scale, complete academic level and complete subject category has formed, which greatly satisfies the strong demand for engineering talents in all economic fields of China. In June 2016, China became the official member of the international undergraduate engineering degree mutual recognition agreement (namely "Washington Accord"), marking that China's engineering education is in the line with the international mainstream engineering education system.

However, along with the deepening of reform and the transformation of traditional industry, the problems existing in the traditional education mode of higher engineering education in China have gradually emerged. 


\section{Difference between the cultivated talents by traditional mode and industrial demand in the "new era"}

At present, the lagging nature of engineering education is reflected in that the advanced engineering talents are difficult to meet the needs of new economy in some aspects (Wu, Hou, Yang \& Hao, 2017). The engineering talents with craftsman spirit and skills in the field of basic engineering are scarce. The "high-level knowledge and low ability" of engineering students in colleges and universities is a social problem. In addition, the development of society is changing with each passing day, and the transformation period of knowledge achievements has greatly shortened compared with that in the previous industrial revolution. However, it is difficult to integrate new achievements, new techniques and new processes in a single education way so that students' knowledge and skills are out of touch with social needs. Traditionally, teachers who mainly undertake the task of imparting knowledge and skills are not able to fulfil the task of educating people in all directions and individuation even though they have tried their best.

\section{Difference between the traditional education mode and the needs of people}

The traditional education system of engineering often takes curriculum as the unit, classroom teaching as the core, campus (classroom) as the main place, teachers as the main body of imparting knowledge to carry out teaching and educating activities. What students can touch is usually solidified knowledge in books, simple skills training in the laboratory controlled environment, as well as the project scene described by teachers. The ability to acquire knowledge and quality is often not what is most desirable to be acquired by an educated person. Under the new economic background, the education system needed by the educated people should be a new education system guided by the social demand, which can promote the combination of multiple education links of self-learning, lifelong learning and individualized learning. The educated people can obtain the individualized differentiation knowledge content in this system. In contrast, the traditional education mode of engineering is characterized by single way, old content, lack of adaptability and flexibility.

\section{Differences between traditional education environment and requirement of talent growth}

The popularization and dissemination of a series of subversive "high, fine and sharp" science and technology guided by information technology in the educational environment of colleges and universities has transformed the traditional asymmetric one-way implantation of engineering knowledge into the interactive exchange of teaching information sharing. As a result, teaching methods and modes, teaching resources and conditions, as well as teachers' needs and structure are not adapted to each other. At the same time, the educated people in the information society environment have a strong demand for getting rid of the constraints of pure classroom and books, which requires that the education environment should change from a classroom-oriented education environment that pursues purely academic performance into an education environment of the unity of knowledge and action, and the engineering training environment that can respond to, participate in and solve the emerging social problems.

Therefore, according to the requirements of new engineering construction, a multi-party cooperative education mode is discussed that takes meeting the needs of human beings as the core and the social needs as the orientation. Then a multi-party cooperative education mode which conforms to the training standards of 
Zhang, Zhang, Zhang, Liu, Yuan, Shi / Exploration and Practice of Multi-Party Cooperative Education Mode Under the ...

water supply and drainage science and engineering professional talents is constructed and applied in the whole course of higher engineering education.

\section{Cooperative education mode of "family-school-internship unit-society"}

Table 1

Main Education Goals of 'Family-School-Internship Unit-Society'

\begin{tabular}{|c|c|}
\hline Links & Main graduation requirements to be reached \\
\hline \multirow{2}{*}{$\begin{array}{l}\text { Family-based } \\
\text { education }\end{array}$} & $\begin{array}{l}\text { Professional norm: to have the humanistic and social science accomplishment and social } \\
\text { responsibility, to understand and obey the engineering professional norm in the } \\
\text { engineering practice and to fulfil the responsibility }\end{array}$ \\
\hline & $\begin{array}{l}\text { Lifelong learning: to have the consciousness of independent learning and lifelong } \\
\text { learning, and the ability of continuous learning and adapting to development }\end{array}$ \\
\hline \multirow{4}{*}{$\begin{array}{l}\text { School-based } \\
\text { education }\end{array}$} & $\begin{array}{l}\text { Engineering knowledge: to have the ability to use mathematics, natural sciences, } \\
\text { engineering foundations and expertise to solve complex engineering problems }\end{array}$ \\
\hline & $\begin{array}{l}\text { Problem analysis: can apply the basic principles of mathematics, nature and engineering } \\
\text { science, to identify, express, and analyze complex engineering problems through literature } \\
\text { research so as to obtain effective conclusions }\end{array}$ \\
\hline & $\begin{array}{l}\text { Study: to study complex engineering problems based on scientific principles and to obtain } \\
\text { reasonable and effective conclusions through information synthesis by using scientific } \\
\text { methods, including experiment design, analysis and data interpretation }\end{array}$ \\
\hline & $\begin{array}{l}\text { Use of modern tools: to be able to develop, select and use appropriate technologies, } \\
\text { resources, modern engineering tools and information technology tools for complex } \\
\text { engineering problems, including prediction and simulation of complex engineering } \\
\text { problems, and to be able to understand their limitations }\end{array}$ \\
\hline \multirow{3}{*}{$\begin{array}{l}\text { Internship } \\
\text { unit-based } \\
\text { education }\end{array}$} & $\begin{array}{l}\text { Design / development of solutions: to be able to design solutions for complex engineering } \\
\text { problems, to design systems, units (components) or process flows that meet specific } \\
\text { requirements, and to be able to reflect innovative awareness in the design process with } \\
\text { taking into account social, health, safety, legal, cultural and environmental factors }\end{array}$ \\
\hline & $\begin{array}{l}\text { Engineering and society: to be able to make a reasonable analysis based on engineering- } \\
\text { related background knowledge, to evaluate the impact of professional engineering practice } \\
\text { and complex engineering solutions on society, health, safety, law and culture, and to } \\
\text { understand the responsibilities to be undertaken }\end{array}$ \\
\hline & $\begin{array}{l}\text { Professional norm: to have humanistic and social science accomplishment and social } \\
\text { responsibility, to understand and obey the engineering professional norm, and to fulfill } \\
\text { the responsibility }\end{array}$ \\
\hline
\end{tabular}

Project management: to understand and master the principles of engineering management and economic decision-making methods, and to be able to apply in multi-disciplinary environment

Environment and sustainable development: to be able to understand and evaluate the impact of engineering practice on the environment and social sustainable development for complex engineering problems

Society-based Individuals and teams: to be able to assume the role of individual, team member, and education person in charge in a team in a multidisciplinary context

Communication: to be able to effectively communicate with industry colleagues and the public on complex engineering issues, including report writing and document design, presenting statements, expressing or responding to instructions clearly

Note. "Graduation requirements" in the table refers mainly to the graduation requirements of the general standards in the engineering education certification standards.

The multi-party cooperative education mode of water supply and drainage science and engineering mainly consists of four aspects: the family and school where the educated people are located, the internship unit where they completes the project training, and the society that they contact with during the course of study, so as to give full play to the advantages of different ways of educating people and training new engineering talents meeting the requirements of the new era. The "family-school-internship unit-society" cooperative education 
Zhang, Zhang, Zhang, Liu, Yuan, Shi / Exploration and Practice of Multi-Party Cooperative Education Mode Under the ...

$\overline{\text { mode (shown in Table 1), 1) trains students' healthy psychological quality and correct attitude toward the world }}$ by virtue of the advantage of family affection to guide students to establish patriotic feelings and grateful thinking; 2) relies on the professional education platform of the school to train students with solid professional knowledge and basic business skills to promote the overall improvement of students' engineering quality; 3 ) deepens "school-enterprise cooperation" scientifically, promotes the integration of production and education in an all-round way, trains students to meet the actual post requirements and communicate with professionals and promotes students to gradually have the attitude of devotion to work and craftsmen spirit with the advantages of practical training; 4) trains students with the ability to respond to the social needs and solve the complex practical problems so as to stimulate the value orientation of using what has learned and repaying for their hometown through the complex education environment of the society.

\section{Cooperative education implementation strategy of "family-school-internship unit- society"}

\section{Enhancing psychological quality and gratitude consciousness of college students through family emotion education}

The obvious characteristic of higher education lies in that the relatively mature students are conducting independent learning in an environment far away from the family environment guided by the teachers, and the learning objectives are accomplished by self-discipline. On the one hand, parents rely more on school education for their children. On the other hand, schools have no better way to restrain students than school rules and discipline, and emotional education is more difficult to achieve universal results for higher education units. For this problem, we can do a good job in emotional education with parents by means of centralized talk and individual communication. For example, at the beginning of freshmen's entrance, we can hold a parents' meeting to introduce the professional advantages of schools, the direction of employment in the future, students' growth requirements and school discipline, which is helpful to attract excellent students. During the study period, non-regular communication with parents about the growth of students and achievement should be carried out. In particular, students shall be encouraged to use the material rewards obtained during the study period to give gifts to family members so as to deepen the emotions. Before and after employment, it is suggested that parents should actively guide students to cope with social competition by continuing their studies, and introduce to them about how to correctly understand the world so as to internalize and externalize their sense of social responsibility.

Cultivate learning ability and professional skills of college students through professional education in schools

Teaching and educating people is the most basic and core work in colleges and universities. However, influenced by the traditional education, teachers' time and energy are more inclined to teaching and evaluating students' knowledge of textbook. However, the engineering talents required by the new engineering are more able to solve complex engineering problems, to communicate and cooperate with others, and to observe professional norm consciously. This requires that we should devote more energy to the all-round development 
Zhang, Zhang, Zhang, Liu, Yuan, Shi / Exploration and Practice of Multi-Party Cooperative Education Mode Under the ...

of students when teaching. In order to solve this problem, first of all, we can invite senior professors or wellknown experts of engineering to hold professional introduction and academic guidance lectures for freshmen who have just begun to carry out the entrance education of engineering to cultivate their interest in learning and define their learning goals. In addition, promotional films (such as "Super Engineering") capable of display project achievements can also be played to motivate students. Secondly, we can guide the students to use modern science and technology to train their professional skills on the basis of mastering the theory of professional knowledge so as to make the students interested in using professional knowledge (Yin, Xue and Xu, 2014). In addition, students can also be guided to apply their core skills in a comprehensive way (Ling, 2018). Professional-based innovative entrepreneurship training can be carried out combined with professional fields such as accounting, marketing and law so as to improve communication between students and personnel in other fields and express professional knowledge and develop their leadership (McClure, 2015; National Science Board, 2016; Eesley \& Miller, 2017).

\section{Training practical operation skills of college students through the internship unit education}

Under the condition of market economy, some enterprises have weakened their willingness and condition to train students after reform and transformation, but this link is indispensable for the training of engineering talents. In order to arouse the enthusiasm of enterprises and their professional and technical personnel to participate in the training of engineering talents, active and effective measures shall be taken to deepen the "school-enterprise cooperation", including 1) going out, publicizing the school's professional characteristics to the enterprises, and actively expressing the school-enterprise cooperation through various platforms and opportunities; 2) introducing, adjusting the course system according to the engineering education standard and inviting the enterprise personnel to hold lectures and even undertake a certain teaching link in school; 3) providing honor, issuing the matching plaque, appointment letter and golden flag for the unit and personnel that can cooperate well with the school to finish the student training to show their contribution to the higher education; 4) setting expenditure, appropriate economic subsidy shall be given to the enterprise or the professional personnel serving the training task of the students within the scope permitted by the teaching expenditure and the financial system so as to form a long-term incentive mechanism of mutual benefit. It can also effectively encourage enterprises to actively explore and improve the practice of educating people, promote "integration of production and education".

\section{Promoting college students to further understand social and professional responsibilities through social environment education}

Whether or not to meet the social needs is an important criterion for testing the quality of engineering personnel training, and also a basis for judging the effectiveness of new engineering construction. In order to better adapt to the development of society in the future, students are required to know more about society during their study period. The effective ways are as follows. Firstly, we should guide students to actively observe the social problems related to the major through the network and other media, and help students to sort out these viewpoints and ideas so as to cultivate their awareness of the state of social development at all times. Secondly, 
Zhang, Zhang, Zhang, Liu, Yuan, Shi / Exploration and Practice of Multi-Party Cooperative Education Mode Under the ...

$\overline{\text { we will organize students to carry out social practice activities related to professional needs, investigate the }}$ society from the professional perspective, and put forward solutions or suggestions to social practical problems or needs. Thirdly, students are encouraged to use their knowledge comprehensively to express the social problems, solutions and expected results related to their majors to their neighbors and friends so as to promote the construction of projects in this field in their hometown and improve their sense of acquisition for professional skill learning.

\section{Conclusions}

According to the requirements of talents training of new engineering, a basic, professional, comprehensive and innovative practical teaching system has been constructed, which is organically combined with theoretical teaching and relatively independent (Shen \& Wu, 2013). It is the basic way to improve students' engineering ability and multi-party collaborative education mode is a useful supplement to the practical teaching system. Through implementing the above-mentioned education mode and strategy, Hebei Agricultural University's water supply and drainage science and engineering major has carried out eight social practice activities, completed two excellent research reports, and won 11 provincial-level and above prizes in the training competition for innovation and entrepreneurship in the past 3 years. In the process of implementation, the engineering quality and humanistic accomplishment of the educated people have been trained and improved. The professional social reputation and education achievements have been praised and commended, the professional level of teachers and the sense of acquisition in education have been developed and satisfied, and the innovation level and the quality of the employees of the enterprises in the related industries have been improved continuously, achieving win-win effect for multi parties.

\section{References}

Eesley, C.E., \& Miller, W. F. (2017). Impact: Stanford University's Economic Impact via Innovation and Entrepreneurship. California: Stanford University, 29-52.

Lin, J. (2017). New engineering construction: create "excellent plan" upgrade version vigorously, Research in Higher Education of Engineering, 3, 7-14.

Ling, H. R. (2018). On the cultivation of college students' practical ability from the perspective of "double creation education". Theory and Practice of Education, 38(27), 15-17.

McClure, K. R. (2015). Exploring curricular transformation to promote innovation and entrepreneurship: An institutional case study. Innovative Higher Education, 40(5), 429-442. https://dx.doi.org/10.1007/s10755015-9325-8

National Science Board. Science and engineering indicators (2016). The United States: National Science Foundation.

Shen, S. X., \& Wu, Y. Y. (2013). Design and construction of practical teaching road map in agricultural colleges. Higher Agricultural Education, (7), 7-9. https://dx.doi.org/10.3969/j.issn.1002-1981.2013.07.002

Wu, A. H., Hou, Y. F., Yang, Q. B., \& Hao, J. (2017). Accelerating development and construction of emerging 
Zhang, Zhang, Zhang, Liu, Yuan, Shi / Exploration and Practice of Multi-Party Cooperative Education Mode Under the ...

engineering taking initiative to adapt to and lead the new economy, Research in Higher Education of Engineering, 1, 1-8.

Yin, B. C., Xue, B. Y., \& Xu, F. (2014). Study on the cultivation model of integrated talents of plant protection discipline "specialty - study - employment - entrepreneurship". Journal of Agricultural University of Hebei (Agriculture and Forestry Education), 16(2):41-43. https://dx.doi.org/10.13320/j.cnki.jauhe.2014.0046

Zhong, D. H. (2017). Connotations and Actions for Establishing the Emerging Engineering Education. Research in Higher Education of Engineering, 3, 1-6. 